\title{
Cross-Sale In Integrated Supply Chain System
}

Bin Shao, West Texas A\&M University, USA

Kunpeng Li, Sam Houston State University, USA

\begin{abstract}
In this article, we study two manufacturers, each producing a single substituting product, selling the products through their own centralized distribution channels, and also using each other's distribution channel at their choice. Distribution channels are also substitutable. Using price competition and a game theoretic approach, we find that the same products can be sold at a higher price in the cross-sale channel than in its own centralized distribution channel. The first mover in doing a cross-sale doesn't necessarily enjoy the advantage in terms of higher profit. Not only manufacturers can charge higher prices for their own and cross-sold product from their competitor, but also cross-sale increases the profits of both manufacturers; and most importantly, cross-sale improves the system's profit dramatically.
\end{abstract}

Keywords: Cross-Sale; Product Substitutability; Channel Substitutability; Supply Chain

\section{INTRODUCTION}

n practice, businesses define cross-sale in many different ways. In supply chain system, cross-sale is usually defined as selling products through different distribution channels and is commonly observed in practice. For example, Dell sells its products through its own centralized distribution channel (dell.com) and also through other channels, like BestBuy, Wal-Mart (walmart.com), etc. On the other hand, Dell also sells its competitors' products in its centralized channel. For example, Dell not only sells its brand name, but also sells Canon, Epson, Kodak, Lexmark, etc.

Depending upon the manufacturer's decision, three different channel structures may rise - exclusive system (where both manufacturers sell their products exclusively through their own centralized systems), partially crosssale system (where one manufacturer sells in both channels and the other sells only in its centralized channel), and complete cross-sale system (where both manufacturers sell products in both parties' channels). We use price competition and a game theoretic approach to model the above framework. This paper is intended to answer the following questions: "Is it always beneficial to have cross-sale in terms of charging higher prices and obtaining more profit?" and "How do product substitutability and channel substitutability affect a cross-sale decision?"

\section{LITERATURE REVIEW}

One stream of literature is about supply chain system (in)efficiency, channel conflict, and mechanism to achieve coordination. A comprehensive review of this stream is provided by Cachon (2003). This stream typically considers a single manufacturer selling identical products through different channels; for example, exclusive retailer, internet, or a hybrid channel. Ahn et al. (2002) study the competition between decentralized retailers and manufacturer's centralized distribution channel under price competition. Chiang (2003) finds that a single manufacturer may sell the product through direct channel to alleviate the double marginalization observed in the decentralized retail channel. Tsay and Agarwal (2004) review the modeling of channel conflict and coordination. Our work focuses on cross-sale between channels instead of coordination and considers two manufacturers selling substitutable products through integrated distribution channels. 
The two-manufacturer/two-distribution channel system has been studied by marketing and operations literature from different perspectives. Two distribution channels can be either centralized (owned by the manufacturers) or decentralized (owned by independent retailers). McGuire and Staelin (1983) study the impact of product substitutability on Nash equilibrium channel configurations and they further extend their research by incorporating quantity discount and various cost structures into their model (1986). Cachon et al. (2008) and Chiou (2009) address the effect of large product variety on consumers and retailer. Also, many researchers are interested in how vertical competition strategies affect channel performance under various pricing strategies in a decentralized supply chain system, like Moorthy (1987, 1988), Gupta and Loulou (1998), and Lee and Staelin (1997). Cross-sale does not occur in any of these papers.

Within the framework of exogenous channel configurations and multiple retailers, Choi (1996) studies price competition under product and retailer differentiations for different decentralized channel configurations. Moner-Colonques el al. (2004) find that retailer differentiation drives cross-sale under price competition in a decentralized channel system, but there will be no cross-sale if retail store differentiation is not observed in the above two articles. Our work studies whether cross-sale is a beneficial strategy for centralized manufacturers.

\section{MODEL}

Consider two substitutable products, denoted by 1 and 2 , produced by two manufacturers. The two manufacturers, denoted by $M_{1}$ and $M_{2}$, each have their own centralized distribution channels, denoted by $D_{1}$ and $D_{2}$, respectively. Each product is certainly sold through the manufacturer's centralized system and may also be sold through the other manufacturer's distribution channel. The two channels are also substitutable. Product substitutability and channel substitutability create different competition dimensions. One dimension of competition is introduced by considering cross-sale decision between different channels, while the other dimension of competition is introduced by substitutable products. Several multi-channel distribution systems are considered.

Figure 1 schematically describes these configurations. The exclusive system (denoted by E) is a fully integrated system where each manufacturer produces its own product and sells it through a centralized channel. It serves as a benchmark for the cross-sale systems. The partial cross-sale system (denoted by PC) involves one manufacturer who produces and sells its product (product 1) through its own centralized channel exclusively, while the second manufacturer produces and sells its product (product 2) through both its own centralized channel and the retailing channel owned by the first manufacturer. The first manufacturer makes stocking decisions of product 2 sold in its channel. Certainly in this configuration, the positions of manufacturers are interchangeable. The complete cross-sale system (denoted by $\mathrm{C}$ ) involves both manufacturers selling their products not only through their own integrated channel,but also through the competitor's channel, in which both manufacturers make stocking decisions of each other's product sold in their channels serving their own interests.

Without loss of generality, we assume the common marginal production cost for each product is 0 , no fixed cost of production is considered, and that the production and delivery are assumed to be instantaneous. One manufacturer produces as the other manufacturer's order under a wholesale price contract when cross-sale occurs. Let $w_{1}$ and $w_{2}$ be the wholesale prices of products 1 and 2. Manufacturer 1 not only sets the retail price of its own product, product 1, sold through its own channel, denoted by $p_{1}$, but also the retail price of manufacturer 2's product, product 2, denoted by $p_{12}$, when it is sold through $M_{1}$ 's integrated channel. Similarly, manufacturer 2 sets the retail price of product 2 sold in its own channel, denoted by $p_{2}$, and the retail price of product 1 , denoted by $p_{21}$, when it is sold through $M_{2}$ 's integrated channel. 


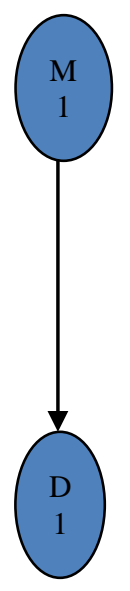

p1

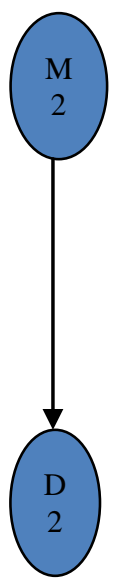

$\mathrm{p} 2$

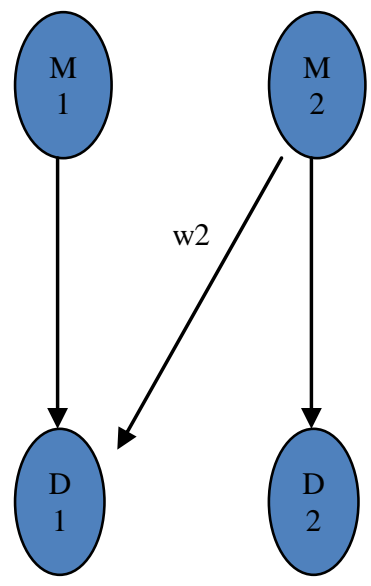

$\mathrm{p} 1, \mathrm{p} 12$ $\mathrm{p} 2$

Partially Crosssale System

(PC)

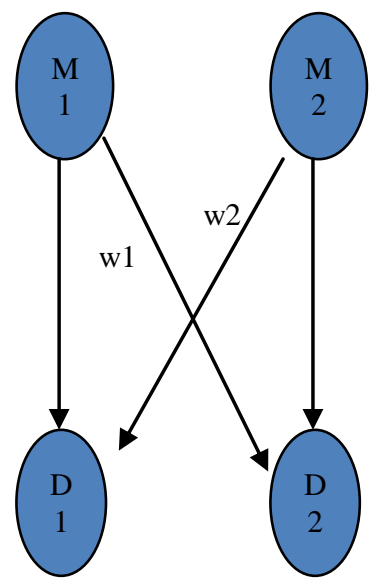

$\mathrm{p} 1, \mathrm{p} 12$

$\mathrm{p} 2, \mathrm{p} 21$
Exclusive

System (E)

Figure 1: Cross-Sale Distribution System Configurations

The competition is modeled by the following demand functions when there is no cross-sale.

$q_{i}=1-p_{i}-(\alpha+\beta)\left(p_{j}-p_{i}\right), i, j=1,2, i \neq j$

where $q_{i}, i=1,2$, is the demand for product $i, \alpha$ denotes channel substitution, and $\beta$ denotes product substitution.

In particular, the products are perfectly differentiated when $\alpha=\beta=0$. The products are nearly identical as $\alpha+\beta$ approaches infinity. This type of demand function is standard in economics and marketing literature modeling product substitutability (Gal-Or, 1991; Raju et al., 1995). Moreover, Lee and Staelin (2000) show that a linear demand function involving substitutable products is indeed consistent with reasonable buyer behavior and market characteristics.

$\Pi_{M i}^{j}$ is used to denote the profit of manufacturer $M_{i}$ for a specific configuration $j$, where $i=1,2$ and $\mathrm{j}=\mathrm{E}, \mathrm{PC}, \mathrm{C}$. The total supply chain profit (the sum of the profits of manufacturers) under configuration $j$ will be denoted by $\Pi^{j}$ (no subscripts). of $M_{i}$ is

The exclusive system serves as a benchmark for the cross-sale systems. The profit maximization problem

$\max _{p_{i}} p_{i}\left(1-p_{i}-(\alpha+\beta)\left(p_{j}-p_{i}\right)\right)$, where $i, j=1,2, i \neq j$.

The solution of the above optimization problem yields the following results. 
$p_{1}^{*}=p_{2}^{*}=\frac{1}{\alpha+\beta+2}, q_{1}^{*}=q_{2}^{*}=\frac{\alpha+\beta+1}{\alpha+\beta+2}$

$\Pi_{M 1}^{E *}=\Pi_{M 2}^{E *}=\frac{\alpha+\beta+1}{(\alpha+\beta+2)^{2}}, \Pi^{E *}=\frac{2(\alpha+\beta+1)}{(\alpha+\beta+2)^{2}}$.

For the reason of brevity, between partial cross-sale system (PC) and complete cross-sale system (C), only $\mathrm{C}$ is described here. $\mathrm{PC}$ will have similar formulations.

Under a cross-sale system, both manufacturers sell their products through both their own integrated channel and the competitor's channel. $M_{i}$ sets the whole sale price $w_{i}$ for $M_{j}$ to buy product $i$ and sell it in its channel. $M_{j}$ sets the retail price of product $i$, denoted by $p_{j i}$. So the demand function (1) is extended to

$q_{1}=1-p_{1}+(\alpha+\beta)\left(p_{2}-p_{1}\right)+\beta\left(p_{12}-p_{1}\right)+\alpha\left(p_{21}-p_{1}\right)$,

$q_{2}=1-p_{2}+(\alpha+\beta)\left(p_{1}-p_{2}\right)+\alpha\left(p_{12}-p_{2}\right)+\beta\left(p_{21}-p_{2}\right)$,

$q_{12}=1-p_{12}+\beta\left(p_{1}-p_{12}\right)+\alpha\left(p_{2}-p_{12}\right)+(\alpha+\beta)\left(p_{21}-p_{12}\right)$,

and $q_{21}=1-p_{21}+\beta\left(p_{2}-p_{21}\right)+\alpha\left(p_{1}-p_{21}\right)+(\alpha+\beta)\left(p_{12}-p_{21}\right)$,

where $q_{i}$ is the demand for product $i$ sold in $M_{i}$ 's channel, $q_{i j}$ is the demand of product $j$ in $M_{i}$ 's channel, and $p_{i}$ and $p_{j i}$ are the prices of the same product $i$ sold in different channels $(i, j=1,2, i \neq j)$.

The profit maximization problem of manufacturer $M_{i}$ is

$\Pi_{M i}^{C}=p_{i} q_{i}+\left(p_{i j}-w_{j}\right) q_{i j}+w_{i} q_{j i}$, Where $, i, j=1,2, i \neq j$.

The first order conditions (it is easy to verify that the second order conditions are satisfied) yield:

$p_{i}^{C *}\left(w_{1}, w_{2}\right)=f_{i}\left(w_{1}, w_{2}, \alpha, \beta\right), i=1,2$,

$p_{i j}^{C *}\left(w_{1}, w_{2}\right)=f_{i j}\left(w_{1}, w_{2}, \alpha, \beta\right), i, j=1,2, i \neq j$.

and then

$q_{i}^{C *}\left(w_{1}, w_{2}\right)=g_{i}\left(w_{1}, w_{2}, \alpha, \beta\right), i=1,2$

$q_{i j}^{C *}\left(w_{1}, w_{2}\right)=g_{i j}\left(w_{1}, w_{2}, \alpha, \beta\right), i, j=1,2, i \neq j$.

The two manufacturers select their wholesale prices by solving the following problems

$\max _{w_{i}} \Pi_{M i}^{C}=Q_{i}\left(w_{1}, w_{2}, \alpha, \beta\right), i=1,2$.

The equilibrium wholesale prices $w_{1}^{*}$ and $w_{2}^{*}$ can be found by solving the $1^{\text {st }}$ order conditions. Once $w_{1}^{*}$ and $w_{2}^{*}$ are known, the equilibrium prices, quantities, and profits, as well as the total profit, can be calculated accordingly. The whole sale prices, retail prices, order quantities, and manufacturer's profits are symmetric with respect to the two products. This is because of the assumption of symmetric cost structure for the two products. This assumption is not critical to our model; rather, it allows us to compare and contrast different systems elegantly. Similarly, we can solve for the equilibrium prices, quantities, and profits of partial cross-sale system (PC). All of these results can be obtained easily through using Maple or Matlab, but the structures of the results are lengthy. So, for the sake of brevity, we don't list them here. 


\section{RESULTS AND ANALYSES}

\section{Theorem 1}

At equilibrium, the following relationships hold,

(a) $\quad p_{1}^{C}>p_{1}^{P C}>p_{1}^{E}, p_{2}^{C}>p_{2}^{E}$ and $p_{2}^{P C}>p_{2}^{E}$;

(b) $\quad p_{12}^{P C}>p_{2}^{P C}, p_{12}^{C}>p_{2}^{C}$ and $p_{21}^{C}>p_{1}^{C}$.

This theorem captures both the vertical and horizontal changes in prices due to cross-sale.

Part (a) of the theorem states that comparing the retail prices of the three supply chain systems, cross-sale systems allow manufacturers to charge higher retail prices. The retail prices of products 1 and 2 in their own channels are higher in partial cross-sale system than in exclusive system, also higher in complete cross-sale system than in exclusive system. So when we compare configurations of different degrees of cross-sale, we find cross-sale is beneficial in terms of "providing" higher retail prices.

Both $p_{12}$ and $p_{2}$ are the retail prices of product 2. The former is the cross-sale price in manufacturer 1's channel and the latter is the price in its own channel. $p_{21}$ and $p_{1}$ are also the retail prices of the same product, product 1 , but in different distribution channels. Part (b) of the theorem states that within the same cross-sale systems, the same products can be sold at a higher price in the cross-sale channel than in its own centralized distribution channel. This is counter intuitive in the sense that people would think the prices would go down in the cross-sale channel due to more direct competition from the rival.

\section{Theorem 2}

At equilibrium, the following relationships hold,

(a) $\quad \Pi_{M 1}^{P C} \gtrless \Pi_{M 2}^{P C}$;

(b) $\quad \Pi_{M 1}^{C}>\Pi_{M 1}^{P C}>\Pi_{M 1}^{E}$ and $\Pi_{M 2}^{C}>\Pi_{M 2}^{P C}>\Pi_{M 2}^{E}$.

This theorem has important implications. Part (a) states that the first mover in doing cross-sale doesn't necessarily enjoy an advantage in terms of higher profit when only partial cross-sale occurs. The result depends on the degree of product and channel substitutions.

Part (b) says that not only manufacturers can charge higher prices for their own and cross-sold product from their competitor, but also cross-sale does increase the profits of both manufacturers.

\section{Theorem 3}

$\frac{\Pi^{P C}}{\Pi^{E}}, \frac{\Pi^{C}}{\Pi^{E}}$, and $\frac{\Pi^{C}}{\Pi^{P C}}$ are all increasing functions of both $\alpha$ and $\beta$.

Figure 2 illustrates the idea of Theorem 3. Since $\alpha$ and $\beta$ are both greater than $0, \frac{\Pi^{\mathrm{PC}}}{\Pi^{\mathrm{E}}}, \frac{\Pi^{\mathrm{C}}}{\Pi^{\mathrm{E}}}$, and $\frac{\Pi^{\mathrm{C}}}{\Pi^{\mathrm{PC}}}$ achieve their minimums when $\alpha=\beta=0$ and the minimums are $137.5 \%, 175 \%$, and $127.27 \%$, respectively. 

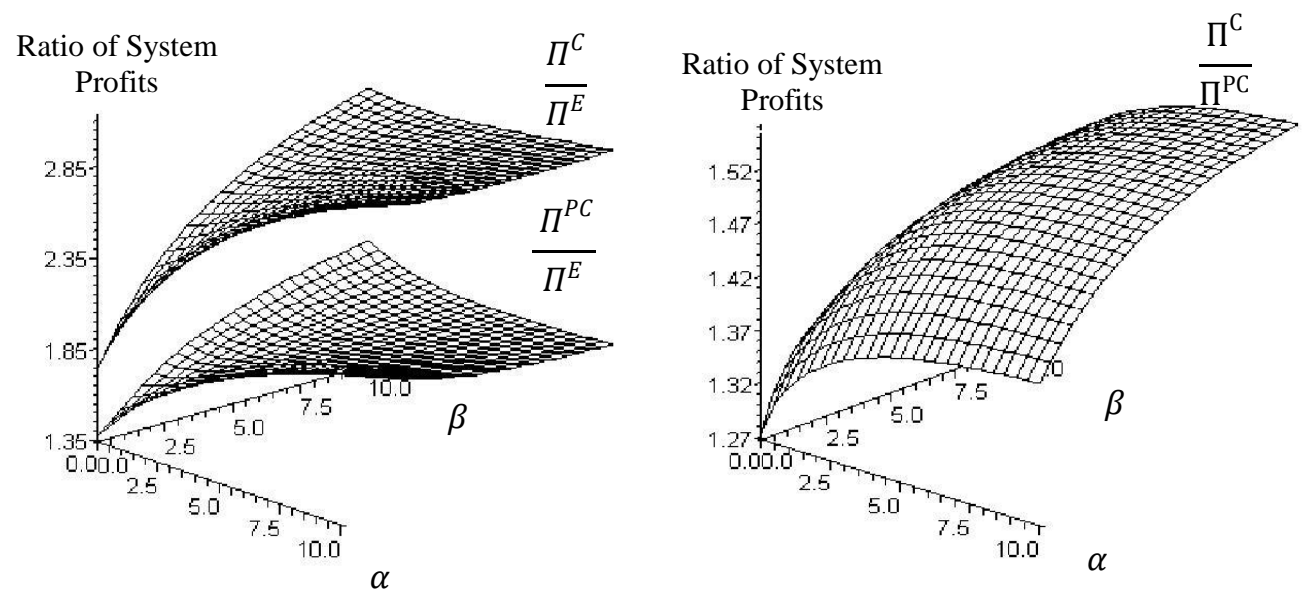

Figure 2: Comparison Among Different Systems

Hence, partial cross-sale can improve the system profit by at least $37.5 \%$ and cross-sale can improve the system profit by at least $75 \%$ compared to no cross-sale at all. Even from partial cross-sale system to full cross-sale system, the total system profit can be further improved by at least $27.27 \%$; so cross-sale does improve the system profit dramatically.

\section{SUMMARY AND CONCLUSIONS}

Cross-sale in the supply chain distribution system is often observed in practice. In this paper, we use price competition and game theoretic approach to model duopoly centralized distribution systems where two manufacturers, each producing a single substituting product, sell the products through their own centralized distribution channels and may also use each other's distribution channel at their choice.

We found that the same products can be sold at a higher price in the cross-sale channel than in its own centralized distribution channel and that the first mover in doing cross-sale doesn't necessarily enjoy an advantage in terms of higher profit. The result depends on the degree of product and channel substitutions. Not only manufacturers can charge higher prices for their own and cross-sold product from their competitor, but also crosssale does increase the profits of both manufacturers; and, most importantly, cross-sale does improve the system profit dramatically for both partial cross-sale and complete cross-sale distribution systems.

Like all other models in marketing or operations literature, our model is not free from assumptions. We assume a zero production cost demand. This allows us to get analytically tractable results and derive interesting insights. Similar assumption has often been made in a lot of literature. Our assumption about the structure of the demand function is also standard in economics, operations, and marketing literature. We consider only a dualchannel centralized distribution system involving two substitutable products. A natural extension is to study a decentralized distribution system involving two manufacturers and two retail outlets which are more commonly observed in reality. Another possible direction of future research is to introduce demand uncertainty into our model. Our model assumes complete information and is symmetric. Relaxing these assumptions can also provide potentially interesting extensions.

\section{AUTHOR INFORMATION}

Bin Shao is an assistant professor in the Department of Computer Information and Decision Management at West Texas A\&M University. She received her Ph.D. in Business Administration from the University of Illinois at Urbana-Champaign. Her research appears in California Journal of Operations Management, Journal of 
Management and Marketing Research, Academy of Information and Management Sciences Journal, and others. E-mail: bshao@mail.wtamu.edu. Corresponding author.

Kunpeng Li is currently an Assistant Professor of Management at Sam Houston State University. She received her $\mathrm{PhD}$ from the University of Illinois at Urbana-Champaign. Her research interests include product design, supply chain management, and interfaces between marketing and operations management. She has published in journals such as Production and Operations Management, International Journal of Knowledge-Based Organizations, California Journal of Operations Management, and others. E-mail: kli@shsu.edu

\section{REFERENCES}

1. Ahn, H., I. Duenyas, and R.Q. Zhang, "Price Competition between Retailers and Manufacturer-Owned Stores," University of California at Berkeley Working paper, 2002.

2. Cachon, G.P., "Supply Chain Coordination with Contracts," Handbooks in Operation Research and Management Science, 11, 2003, 229-340.

3. Cachon, G.P., C. Terwiesch, and Y. Xu, "On the Effect of Consumer Search and Firm Entry in a Multiproduct Competitive Market,” Marketing Science, 27(3), 2008, 461-473.

4. Chiang, W. K., D. Chhajed, and J.D. Hess, "Direct Marketing, Indirect Profits: A Strategic Analysis of Dual-Channel Supply-Chain Design," Management Science, 49(1), 2003, 1-20.

5. Chiou, L., "Empirical Analysis of Competition between Wal-Mart and Other Retail Channels," Journal of Economic Management and Strategy, 18(2), 2009, 285-322.

6. Choi, S.C., "Price Competition in a Duopoly Common Retailer Channel," Journal of Retailing, 72(2), 1996, 117-134.

7. Gal-Or, E., "Duopolistic Vertical Restraints,” European Economic Review, 35(6), 1991, $1237-1253$.

8. Gupta, S., and R. Loulou, "Process Innovation, Product Differentiation, and Channel Structure: Strategic Incentive in a Duopoly," Marketing Science, 17(4), 1998, 301-316.

9. Lee, E., and R. Staelin, "Vertical Strategic Interation: Implication for Channel Pricing Strategy," Marketing Science, 16(3), 1997, 185-207.

10. Lee, E., and R. Staelin, "A General Theory of Demand in a Multi-Product Multi-Outlet Market," Working Paper, Fuqua School of Business, Duke University, 2000.

11. McGuire, T.W., R. Staelin, "An Industry Equilibrium Analysis of Downstream Vertical Integration," Marketing Science, 2(2), 1983, 161-191.

12. McGuire, T.W., R. Staelin, "Channel Efficiency, Incentive Compatibility, Transfer Pricing, and Market Structure: An Equilibrium Analysis of Channel Relationships," Research in Marketing, 8, 1986, 181-223.

13. Moner-Colonques, R., J.J. Sempere-Monerris, A. Urbano, “The Manufacturers' Choice of Distribution Policy under Successive Duopoly," Southern Economic Journal, 70(3), 2004, 532-548.

14. Moorthy, K.S., "Managing Channel Profits: Comment,” Marketing Science, 6(4), 1987, 375-379.

15. Moorthy, K.S., "Strategic Decentralization in Channels," Marketing Science, 7(4), 1988, 335-355.

16. Raju, J.S., R. Sethuraman, and S.K. Dhar (1995), "The Introduction and Performance of Store Brands," Management Science, 41(6), 1995, 957-978.

17. Tsay, A.A, and N. Agrawal, "Modeling Conflict and Coordination in Multi-Channel Distribution Systems: A Review," Handbook of Quantitative Supply Chain Analysis: Modeling in the E-Business Era," Springer, 2004. 


\section{NOTES}

